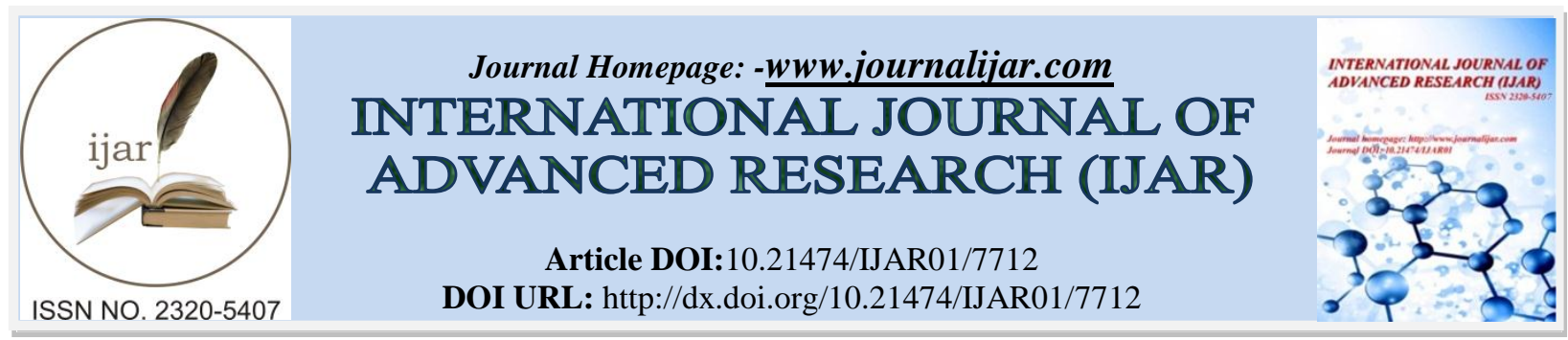

RESEARCH ARTICLE

\title{
CHEMICAL LABORATORY SKILLS MEASUREMENT HIGH SCHOOL STUDENTS: DEVELOPMENT AND VALIDATION.
}

\author{
St. Hayatun Nur Abu ${ }^{1}$, Nurfatimah Sugrah ${ }^{1}$, Nurul Aulia Rahman ${ }^{1}$, Muhammad Danial ${ }^{2}$ and Muhammad \\ Anwar ${ }^{2}$. \\ 1. Chemistry Education Department of Universitas Khairun: Ternate, Maluku Utara, Indonesia. \\ 2. Postgraduate Chemistry Education Department of Universitas Negeri Makassar: Makassar, Indonesia.
}

\section{Manuscript Info}

\section{Manuscript History}

Received: 20 July 2018

Final Accepted: 26 August 2018

Published: September 2018

Keywords:-

Student Laboratory Skills Worksheet, 4D Development, Laboratory Skills, Student's High School.

\begin{abstract}
This study aims to develop the Student Labor Skills Worksheet and implementing to high school students in Ternate City. Development of Laboratory Skills Worksheet are adapted from four development stages (4-D): define, design, develop, and disseminate. While the Implementation of Laboratory Skills Worksheet aims to gather data about the student laboratory's initial skills ofhigh school students in Ternate City for science major in grade X and XI. The samples selected by purposive stratified random sampling. The result of analysis showed that the average of initial skill laboratory at school: (1) A accreditation was 57.72 (medium), (2) B accreditation was 56.50 (medium), (3) C accreditation was 21.39 (low). The average of initial skills laboratory of students was 45.20 in medium category.
\end{abstract}

Copy Right, IJAR, 2018,. All rights reserved.

\section{Introduction:-}

Laboratory is a place to see, try, test, evaluated the science conceptsthat is learned until students gain a better understanding about science [13]. Learning science that is only done through reading books and listening to teacher explanation is not complete without accompanied by science activities that mostly carried out in the laboratory. One of learning that cannot be separated from practicum activity is chemistry lesson. Most of the concepts and theories of chemistry are demonstrated in laboratories. Meanwhile, according to [7], in laboratory learning can also be stimulating high-level thinking skills of learners such as analytical, creative, and critical skills that play an important role in learning chemistry. But in fact, not all schools have adequate laboratory for teaching labs even school that have laboratories sometimes have not utilized the laboratory optimally. That matter has an impact on student laboratory skills.

Laboratory skills are the skills of student use measuring tools, props, calculators, and computer software, to enhance the experience in the laboratory that can support learning in the classroom [9]. Laboratory activities demandingStudents to prove hypotheses, think scientific, observe, and interpreting of data. It should be supported by the students' ability to communicate. Laboratory activities can provide opportunities for students to develop communication skills and enhance learners' self-confidence [10].

The initial skills laboratory include a) working with equipment and chemicals, including: handling procedures, use and maintenance, and a conscious attitude to safety. b) Cooperate with live specimens c) Work environment, develop skills field. Initial skills laboratory are the prerequisite of early learners in using tools to the end of lab work 
done in the laboratory to determine the changes [7]. Practical activities are undertaken to enhance real-life experience in the laboratory that can support classroom learning. Laboratory skills are the most important part when conducting assessments in psychomotor skills. The range of laboratory skills students should possess include: 1) selecting, installing, operating, opening, cleaning and returning equipment, 2) matching equipment, 3) reading measuring instruments with meticulous, 4) handling, preparing and being aware of chemical hazards, 5) detecting, calibrating, and correcting errors in regulating equipment [7].

Based on data obtained from the education office of Ternate about the availability of chemical laboratories in all schools in Ternate City that was not all schools have laboratory, one of them ishigh school Y. Observations and interviews with chemistry teacher, with existing conditionsthe chemistry teachers only able to teach theoretically. While in high school $\mathrm{Z}$ despite having a laboratory, but the practicum implementation was done after the chemistry materials were taught, this was due to the lack of availability of the classroom so that the chemistry laboratory was used as a classroom for learning. Meanwhile, in high school X, although the practicum is only limited to focus materials, it often appears in the national exam when the school has a laboratory. This impacts on students' laboratory skills.Based on the problems that have been described, the researchers want to develop laboratory skills worksheets and implementing in students high school representing schools with accreditation levels A, B and C.

\section{Method:-}

This research aims to develop Student Labor Skills Worksheet. Development of Laboratory Skills Worksheet used adaptation of the development stage of Trianto (2010) covering four development stages: define, design, develop, and disseminate that known as 4-D. The stages are:

1. Define stage was the first stage in the research that isanalysis of laboratory skill indicators.

2. Design stage was the stage of designing Student Labor Skills Worksheet that will be used to gather data and determine the number of questions for grade X and XI, respectively.

3. Development stage was stage of making question for grade X and grade XI, respectively. The final result at this stage was called the prototype. Laboratory skills worksheet prototype then validated by expert content. Based on input from experts, made revisions of prototype. The result of the upcoming revision was tested for readability and implementation to determine the feasibility of the Student Laboratory Skills Worksheet that has been developed.

4. Disseminate stage was the laboratory skill worksheet giving to students high school in Ternate City selected as research sample. The data generated at this stage was then analyzed to know the student'sinitial skill laboratory.

The population in this research was all student of grade X and XI in Senior high School in Ternate City. The sample in this study was chosen by purposive stratified random sampling. In detail the research sample is presented in table 1 .

Table 1:-Sample of Research

\begin{tabular}{|c|c|c|c|}
\hline No & School & Accreditation & Students of grade X and XI \\
\hline 1. & $\mathrm{X}$ & A & 4187 \\
\hline 2. & $\mathrm{Y}$ & B & 101 \\
\hline 3. & $\mathrm{Z}$ & $\mathrm{C}$ & 702 \\
\hline \multicolumn{2}{|r|}{ Total } \\
\hline
\end{tabular}

In this research, the data collected in the form of data validation, test legibility and implementation, as well as the results of initial skills laboratories. Data collection techniques in this research are detailed in the following table 2.

Table 2:-Data Collection Techniques

\begin{tabular}{|c|l|l|l|}
\hline No & \multicolumn{1}{|c|}{ Type of Data } & \multicolumn{1}{c|}{ Instrumen } & \multicolumn{1}{c|}{ Source of Data } \\
\hline 1 & $\begin{array}{l}\text { Results Validation Student's } \\
\text { Laboratory Skills Worksheet }\end{array}$ & Questionnaire & $\begin{array}{l}\text { Chemist, } \\
\text { Chemical Education Expert }\end{array}$ \\
\hline 2 & Legibility of Student & Questionnaire & Student \\
\hline 3 & Initial skills laboratory & Student Laboratory Skills Worksheet & Student \\
\hline
\end{tabular}

The data collected was then analyzed descriptively. A brief description of the technical data analysis used in this research is as follows: 
Validation of Laboratory Skills Worksheet

Data analysis techniques used to analyze data validation results from experts using the formula:

\begin{tabular}{|c|c|c|}
\hline & & $\bar{x}=\frac{\Sigma X}{n}$ \\
\hline$x$ & $:$ & nilai rata-rata \\
\hline$\Sigma \times$ & : & Number of validator assessment answers \\
\hline$N$ & : & Number of validators \\
\hline
\end{tabular}

The validation criteria range of complete calculation results can be observed in Table 3 .

Table 3:-Average Analysis Validation Criteria

\begin{tabular}{|c|c|}
\hline Average & Value of Validity Criteria \\
\hline $3,26-4,00$ & Very Valid \\
$2,51-3,25$ & Valid \\
$1,76-2,50$ & Less Valid (revision) \\
$1,00-1,75$ & Invalid (total revisions) \\
\hline
\end{tabular}

\section{Aalysis of Legibility\& Implementation Test Data}

Technique of data analysis in legibility test by percentage (\%) readability can be calculated with the equation 1 .

\begin{tabular}{|l|l|l|}
\hline & \multicolumn{3}{|c|}{ Percentage of Readability $=\frac{\mathrm{X}}{4} \times 100 \%$} \\
\hline $\mathrm{X}$ & $:$ & average score of student answers \\
\hline 4 & $:$ & number of answers \\
\hline
\end{tabular}

In the implementation test correction of their work result on the laboratory skill worksheet in the form of checklist list. Percentage calculation (\%) of implementation can be calculated by the equation 2 .

Percentage of Implementation $=\frac{\Sigma X}{10} \times 100 \%$

\begin{tabular}{|l|l|l|}
\hline$\Sigma X$ & $:$ & the number of students who answered correctly \\
\hline 10 & $:$ & Total of student \\
\hline
\end{tabular}

\section{Initial skills laboratory}

The data of students 'work on the laboratory skill worksheet were analyzed descriptively using SPSS 20. The students' initial skills were analyzed based on the laboratory skill indicator and based on the items in the worksheet Furthermore, the average student's initial skills laboratory were categorized as in the table 4.

Table 4:-Initial skill categories of student laboratories

\begin{tabular}{|c|c|}
\hline Category & Category \\
\hline $81-100$ & Very High \\
\hline $61-80$ & Height \\
\hline $41-61$ & Medium \\
\hline $21-40$ & Low \\
\hline $0-20$ & Very Low \\
\hline
\end{tabular}

\section{Result And Discussion:-}

This research consists of two stages, namely development of student laboratory skill worksheet and student laboratory skill analysis by implementing skill laboratory worksheet that has been developed.

\section{Development of Student Laboratory Skills Worksheet}

This research has two stages: the development of laboratory skill worksheet and the measurement of the students' initial laboratory skills using the developed instrument. The development of a laboratory skill worksheet aims to produce instruments that can be used to measure initial laboratory skills. Before being used to measure laboratory skills, the laboratory skill worksheet was first validated and the test of readability and implementation. 
Development of student laboratory skill worksheet was the first step to produce instrument that can measure initial skill laboratory of student. Initial skills laboratory are the initial skill of students to take action in using measuring tools, developing skills in observation and being scientific. The developed Worksheet adopted the 4D development stage of Thiagarajan, Semmel \& Semmel (1974) [7] covering four development stages: define, design, develop, and disseminate.

The first stage was define. At this stage formulated indicators of laboratory skills. The laboratory indicators on which the Worksheet Skills is built are: (1) Preparing tools and materials according to practical guidance (2) Understanding the function of the practicum tool and using the equipment correctly (3) Designing an experiment (4) Using and reading measuring instruments correctly (5) Handling the safety of the practicum in case of a minor accident (6) Knowing the nature of a product of the experimental results

The second stage was the design stage. At this stage construct the lab work skills grid and determine the number of items for each grade $\mathrm{X}$ and grade XI. The number of question items in each grade X and grade XI was 15 items covering all laboratory skill indicators. Grid about laboratory skills of students of grade X and grade XI more in table 5 .

The laboratory skill worksheet was very valid by the expert. The results of legibility test for the laboratory skill worksheets for grade X and XI were $82.14 \%$ and $85 \%$. To know the ability of laboratory skill worksheet to be used as laboratory skill measurement tool, it is done the test of implementation in students of grade XII. The aspect of recognize the image was the aspect with the highest percentage that was $81.81 \%$, while the aspect of organize the processing time was the aspect with the lowest percentage of $54.54 \%$ for the grade X and $63.64 \%$ for the grade XI. This indicates that the image contained in the laboratory skill worksheet was clear. The ability of students to organize the time of work on the problem of students' knowledge about the practical activities. Still the lack of student knowledge about the practicum implementation makes it difficult for them to answer several questions in the worksheet.

The third stage was the development stage. At this stage consists of some activity namely:

1. Preparation of questions for each grade $X$ and grade XI. After compiling the laboratory skill works grid then next compile the questions, formulate the answers and determine the scoring guidelines.

2. After the question for each indicator was completed, then the problem will be arranged in the student laboratory skill worksheet

3. Expert Validation

Table 5:-Grid Problem Laboratory Skills Grade X and Grade XI

\begin{tabular}{|c|c|c|c|c|c|}
\hline \multirow[t]{2}{*}{ No } & \multirow[t]{2}{*}{ Indicator } & \multicolumn{2}{|c|}{ Grade X } & \multicolumn{2}{|c|}{ Grade XI } \\
\hline & & $\begin{array}{c}\text { Total of } \\
\text { Questions }\end{array}$ & $\begin{array}{l}\text { Number of } \\
\text { Questions }\end{array}$ & $\begin{array}{c}\text { Total of } \\
\text { Questions }\end{array}$ & $\begin{array}{c}\text { Number of } \\
\text { Questions }\end{array}$ \\
\hline 1. & $\begin{array}{l}\text { Prepare tools and materials } \\
\text { according to practical instructions }\end{array}$ & 1 & 15 & 5 & $\begin{array}{c}1,3,7,10 \\
15\end{array}$ \\
\hline 2. & $\begin{array}{l}\text { Understand the functionality of the } \\
\text { tool \& can use the tool properly }\end{array}$ & 5 & $1,2,3,6,13$ & 3 & $2,5,6$ \\
\hline 3. & Designing an experiment & 3 & $4,7,14$ & 1 & 8 \\
\hline 4. & Use and read the meter correctly & 1 & 8 & 2 & 4,9 \\
\hline 5. & $\begin{array}{l}\text { Conduct safety of the practicum in } \\
\text { case of a minor accident }\end{array}$ & 2 & 9,10 & 2 & 11,12 \\
\hline 6. & $\begin{array}{l}\text { Know the nature of a product of the } \\
\text { experimental results. }\end{array}$ & 3 & $5,11,12$ & 2 & 13,14 \\
\hline & Total & 15 & & 15 & \\
\hline
\end{tabular}

The stages after generating the student laboratory skill worksheet was to validate the laboratory skill worksheet by expert validation method. Expert validation was chosen on the grounds to obtain various criticisms and inputs in the process of developing student laboratory skill worksheets that was ready to be used to measure the early skills of high school laboratory students of class X and XI. In this validation process, wasimplemented by appointing 2 
lecturers who are considered experts in the field of chemical education and experts in chemistry. There were 4 main aspects in the validation of the laboratory skill validation work by experts, such as: 1. Material aspect, 2 . language aspect, 3. construction aspect, 4. aspect of time.Full Validation results by experts on the diagram of Figure 1.

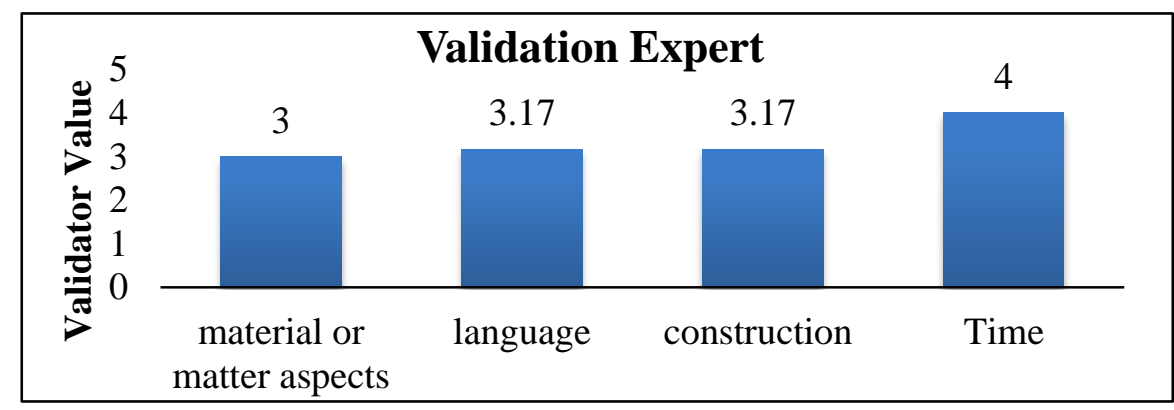

The material aspect was valid by the validator with an average value of 3 . It means that the conformity of the problem with the initial laboratory skill indicator, the formulation of the obvious question and the question includes the initial skills of the laboratory.

Language aspects and construction aspects declared valid by the validator with an average value of 3.17. This means that the language used in the laboratory skill worksheets using the language in accordance with Indonesian language rules does not result in multiple interpretations and the terms used are easily understood by students. While from the aspect of construction validator assessment states that the instructions to do the question, the sentence question or command is clear in the matter stated clearly,

TimeAspects was the aspect that gets the highest assessment of the assessment results of the validator that the average of 4 with the category was very valid. This means that it was used according to the set time. Time 90 minutes is an appropriate time for students to work on a laboratory skill workbook consisting of 15 items of questions.

In general, the assessment of two experts on the student laboratory skills the worksheet developed was 3.34 to be in a very valid category. That is, the laboratory skill worksheet can be used to measure the initial skills of laboratory students of high school grade X and grade XI. At this stage, the validator also provides revised suggestions on the student's Laboratory Skills Worksheet. The suggestion of the revision validator from the worksheet was that the language on the problem and the use of the image should be clearer.

\section{Readability \& Performance Test}

Test legibility and implementation was done by 10 students of high school class XII. In the legibility test conducted an assessment of the ease students answer questions on laboratory skills. The test was performed to determine the extent to which the Laboratory Skills Worksheet can measure students' laboratory skills. The results of the readability test and the performance test in table 6and figure 2 . Based on table 6 , it can be seen that the percentage of reading laboratory skill readability for grade X and XI were $82.14 \%$ and $85 \%$. While the implementation test to determine the ability of laboratory skills worksheets to serve as a tool of laboratory skills. Test the implementation by conducting trials to 10 grade XII students to work on the laboratory skill sheet.

Table 6:-Test Readabilityof Laboratory Skills

\begin{tabular}{|c|l|c|c|}
\hline No. & \multicolumn{1}{|c|}{ Aspect } & \multicolumn{2}{c|}{ \% Result } \\
\cline { 3 - 4 } & & Grade X & Grade XI \\
\hline 1. & Clarity of instructions / instructions & 85 & 85 \\
2. & Clarity of language & 80 & 85 \\
3. & Image clarity & 80 & 85 \\
4. & Capture an illustration of the picture & 80 & 85 \\
5. & Clarity of questions & 90 & 90 \\
6. & Update information & 75 & 75 \\
7. & Conformity of time and number of items matter & 80 & 90 \\
\hline \multicolumn{2}{|c|}{ Average of all aspect } & $\mathbf{8 2 , 1 4}$ & \\
\hline
\end{tabular}


In class X, the highest Percentage of Readability was aspects of clarity of questions with $90 \%$ readability. This means students can read worksheet lab skills well. Furthermore, clarity of clarity / construction aspect was $85 \%$. For aspects of language clarity, picture clarity, drawing illustration drawings and Suitability of time and number of items question was the same legibility aspect of the student was $80 \%$. While the aspect of information novelty was the aspect with the lowest literacy of students was $75 \%$.

In class XI, the highest percentage of legibility was $90 \%$ on the aspect of clarity of questions and aspects of Conformity of time with the number of question items. Clarity of questions makes it easy for students to answer each item of question in the laboratory skill worksheet according to the time set. Next clarity clue / construction aspect, language clarity, picture clarity, picture drawing attractiveness got the same rating from students that was $85 \%$ legibility. While the aspect of information novelty was the aspect with the lowest literacy of students was $75 \%$. The novelty aspect of information receives the lowest rating from the students because the developed laboratory skill worksheet aims to measure students' early laboratory skills so that the questions are fundamental questions about laboratory knowledge for students in grade X and grade XI.

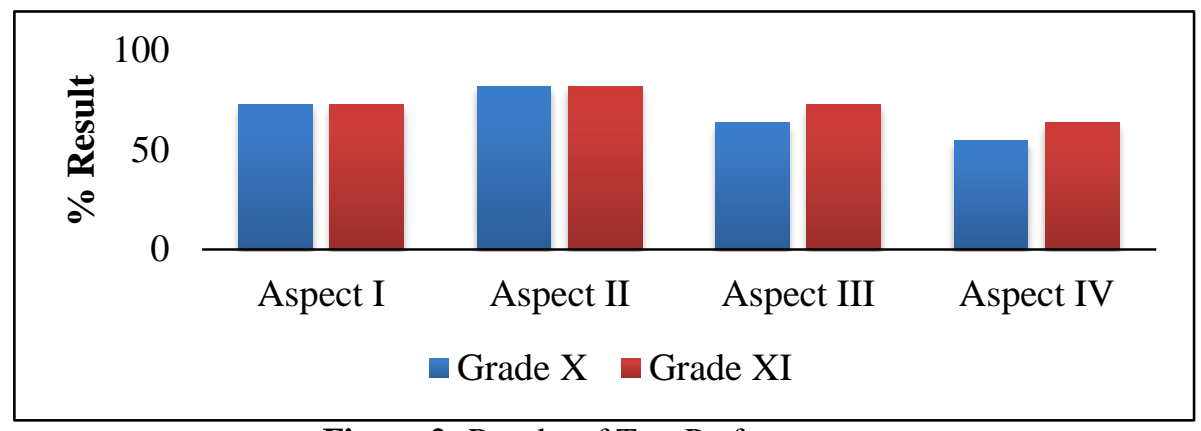

Figure 2:-Results of Test Performance

In the implementation test there are four aspects of the assessment are: 1 . the ability to understand the problem, 2 . the ability to recognize images, 3. Ability to answer questions and 4 ability to organize time of workmanship problems. The results of the implementation test show that the first Aspect was the ability to understand the problem gets the same result for class X and XI was the implementation of $72.73 \%$. The second aspect was the aspect of the ability to recognize the image was the aspect with the highest percentage with the implementation of $81.81 \%$ for class X and XI. The images on the laboratory skill worksheets are presented clearly so as to make it easier for students to recognize the images. While the third aspect was the ability to answer questions, the results of different implementation for classes X and XI are $63.64 \%$ and $72.73 \%$. The difference is due to the difference of questions for classes X and XI. The last aspect to be assessed in the implementation test was the ability to organize the time of questioning was the aspect with the lowest percentage of $54.54 \%$ for class X and $63.64 \%$ for class XI. Percentage of Performance on the aspect of the ability to organize time workmanship problem for class XI higher than class X. It is the same with the results of legibility test, where the percentage of timeliness aspect of the conformity of time with the number of items question in class XI higher than class $\mathrm{X}$

The last stage was the dissemination stage. Laboratory Skills Work Sheet of the disseminated development to measure the initial skills laboratory of Students high school in Ternate City were selected as research samples.

The development of laboratory skill worksheet was expected to be the basis for related parties to find solutions in developing practice activities. Practical activities in the laboratory are more effective to gain observational skills and technical skills, and through these activities the learners are able to achieve three aspects together, namely; (1) The cognitive level in which to understand theory and apply theory to real problems; (2) Affective in planning activities independently, cooperating, and communicating information; and (3) Psychomotor by learning to install the equipment so that it actually runs, using certain instruments and instruments [3]. The addition of affective and psychomotor aspects is important for student assessment during the learning process. Students can more easily understand the theory if proven through the lab so that students get their learning experience [2].

Studying in the laboratory will develop students' understanding of scientific concepts, cognitive enhancement skills, and affective students [6]. The activities in the laboratory as an important part of the curriculum [12]. The laboratory 
activities is an obligation for students who take formal education [12]. It aims to help students prove the theories that have been learned and arouse students' interest in the field of sturdy. [1] which discloses that important attitudes while studying science. Students should have a positive attitude towards the science laboratory when acquiring laboratory skills and scientific content.

In addition, it takes the students skills in the application of skills well. The success of an experiment often depends on the ability to select and use laboratory tools so that it takes a skill. Skills using tools include the skills of selecting tools, preparing tools, assembling tools, using tools for experimental purposes. But the fact, implementation of the practicum in laboratory still encountered many obstacles such as the availability of laboratory facilities and infrastructure or the creativity of teachers in planning and designing practicum activities. It affects the student's laboratory skills.

\section{Analysis of Student Laboratory Skills}

After the test of legibility and implementation, the worksheet was disseminated to high school students in Ternate City to measure the initial laboratory skills. The importance of knowing early student laboratory skills according to [4] that students initial laboratory skills management will result in higher understanding and skills in laboratory chemistry practices.Results of student work on the Laboratory Skills Worksheet were then analyzed based on each laboratory skill indicator. Analysis of student ability based on indicators from the first sample of SMA X can be seen in table 7 .

Table 7:-Analysis of laboratory skills indicators of SMA X

\begin{tabular}{|c|c|c|c|c|c|}
\hline \multirow[t]{3}{*}{ No } & \multirow[t]{3}{*}{ Indicator } & \multicolumn{4}{|c|}{ Result } \\
\hline & & \multicolumn{2}{|c|}{ Grade X } & \multicolumn{2}{|c|}{ Grade XI } \\
\hline & & $\mathbf{A}$ & $\mathbf{B}$ & $\mathbf{A}$ & $\mathbf{B}$ \\
\hline 1 & Prepare tools and materials according to practical instructions & 38 & 61 & 92 & 86 \\
\hline 2 & $\begin{array}{l}\text { Understand the functionality of the tool \& can use the tool } \\
\text { properly }\end{array}$ & 67 & 61 & 44 & 52 \\
\hline 3 & Designing an experiment & 60 & 63 & 95 & 94 \\
\hline 4 & Use and read the meter correctly & 59 & 67 & 30 & 30 \\
\hline 5 & Conduct safety of the practicum in case of a minor accident & 63 & 55 & 56 & 65 \\
\hline 6 & Know the nature of a product of the experimental results. & 38 & 50 & 33 & 37 \\
\hline
\end{tabular}

Based on the table7, shows that the ability of students of grade X and XI in knowing the nature of a product of experimental results was still low.In grade $\mathrm{X}$, indicator of Prepare tools and materials according to practical instructions and Know the nature of a product of the experimental results was 38 it's still low. In grade XI, indicator of use and read the meter correctly and know the nature of a product of the experimental results was the indicator with low student ability. The second sample of SMA Y with accreditation B of the complete data can be seen in Table 8.

Table 8:-Student Laboratory Skills Indicator Analysis of SMA Y

\begin{tabular}{|c|c|c|c|c|c|c|}
\hline \multirow[t]{3}{*}{ No } & \multirow[t]{3}{*}{ Indicator } & \multicolumn{5}{|c|}{ Result } \\
\hline & & \multicolumn{2}{|c|}{ Grade X } & \multicolumn{3}{|c|}{ Grade XI } \\
\hline & & $\mathbf{A}$ & $\mathbf{B}$ & $\mathbf{A}$ & $\mathbf{B}$ & $\mathbf{C}$ \\
\hline 1 & $\begin{array}{l}\text { Prepare tools and materials according to practical } \\
\text { instructions }\end{array}$ & 82 & 89 & 87 & 72 & 83 \\
\hline 2 & $\begin{array}{l}\text { Understand the functionality of the tool \& can use the } \\
\text { tool properly }\end{array}$ & 69 & 62 & 63 & 52 & 29 \\
\hline 3 & Designing an experiment & 72 & 60 & 50 & 63 & 90 \\
\hline 4 & Use and read the meter correctly & 32 & 42 & 34 & 24 & 20 \\
\hline 5 & $\begin{array}{l}\text { Conduct safety of the practicum in case of a minor } \\
\text { accident }\end{array}$ & 63 & 57 & 75 & 44 & 46 \\
\hline 6 & Know the nature of a product of the experimental results. & 40 & 29 & 48 & 24 & 29 \\
\hline
\end{tabular}

Result of student work analysis based on laboratory skill indicator, seen that the lowest percentage was in indicator ability to use and read the measuring instrument correctly. While the ability of students to prepare tools and 
materials in accordance with the practice manual was the indicator with the highest percentage of skills.The third sample of SMA Z with accreditation of $\mathrm{C}$ data can be seen in table 9.

Table 9:-Analysis of laboratory skills indicator of SMA Z

\begin{tabular}{|l|l|c|c|c|c|}
\hline \multirow{2}{*}{ No } & \multicolumn{1}{|c|}{ Indicator } & \multicolumn{3}{|c|}{ Result } \\
\cline { 3 - 4 } & & \multicolumn{3}{|c|}{ Grade X } & Grade \\
\cline { 3 - 4 } & & A & B & C & XI \\
\hline 1 & Prepare tools and materials according to practical instructions & 43 & 43 & 8 & 34 \\
\hline 2 & Understand the functionality of the tool \& can use the tool properly & 15 & 44 & 21 & 15 \\
\hline 3 & Designing an experiment & 19 & 19 & 32 & 18 \\
\hline 4 & Use and read the meter correctly & 6 & 4 & 0 & 1 \\
\hline 5 & Conduct safety of the practicum in case of a minor accident & 32 & 20 & 11 & 25 \\
\hline 6 & Know the nature of a product of the experimental results. & 2 & 9 & 17 & 13 \\
\hline
\end{tabular}

An analysis based on laboratory skill indicator in SMA Z students shows that students' ability to use and read the measuring instrument and to know the nature of a product of the experimental result was a low percentage indicator.In general, the ability of students if analyzed based on laboratory indicator can be seen in Figure 3. Based on the diagram shows that students are able to prepare tools and materials according to practical instructions. However, the ability of students to use and read the measuring tool correctly and to know the nature of a product of the experimental results was still in the low category. While the ability of students to understand the functions, designing experiments, and conduct safety practices in case of minor accidents were in the medium category.

Based on descriptive analysis, Students initial laboratory skills of A, B and C accredited in Ternate City were 57.72; 56.50 and 21.38. The initial laboratory skills of high school with A and B accredited were in the medium category. Because the schools have laboratories but the labs have not been fully implemented. Implementation of practicum in SMA Y was done after the chemistry materials are taught while the practicum implementation in SMA X only limited focused material often appear in the national exam and adjust the availability of tools and materials. In contrast to the A and B accredited, SMA Z (C accredited) students laboratory skills on the low category because the school does not have a chemical laboratory so that teachers only teach chemistry as a theory only. [5] another barrier to lab work in schools: lack of laboratory understanding, exposure and the ability of the science process that prevents students from achieving the desired laboratory goals.

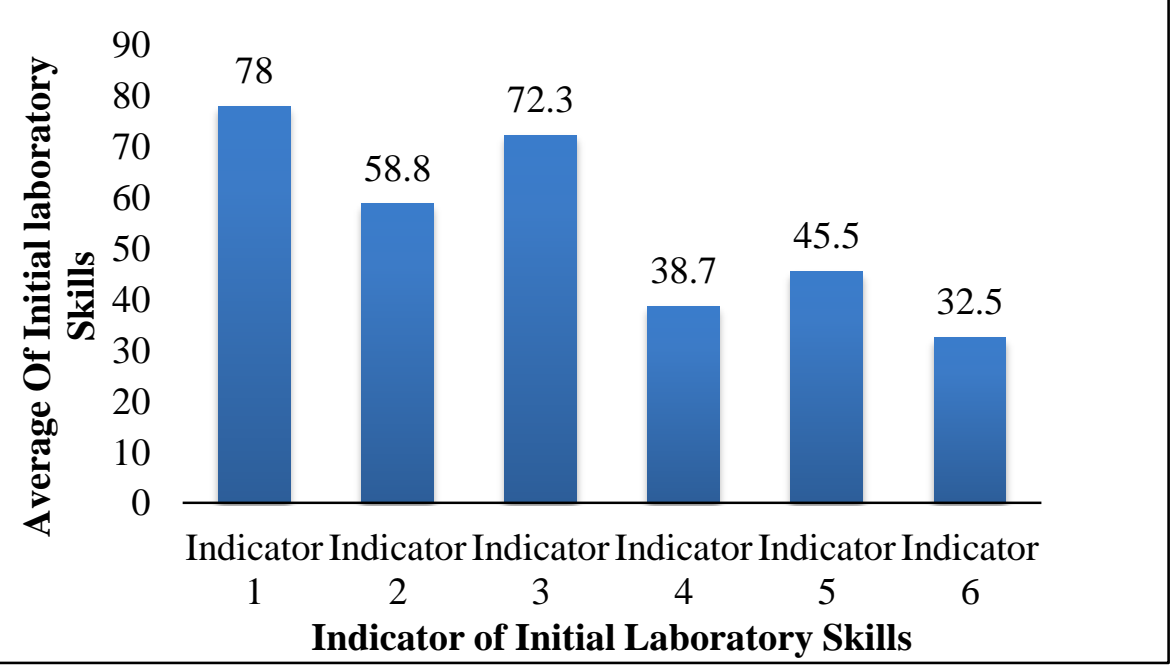

Furthermore, the data were analyzed based on the average ability of students in each school that became the research sample. The first sample wasSMA with accreditation A represented by SMA X. Initial laboratory skill ofSMA X in table 10 . 
Table 10:-Description of initial laboratory skill of SMA X

\begin{tabular}{|l|c|c|c|c|}
\hline \multirow{2}{*}{ Parameter } & \multicolumn{2}{|c|}{ Grade X } & \multicolumn{2}{c|}{ Grade XI } \\
\cline { 2 - 5 } & A & B & A & 39 \\
\hline Minimum & 29 & 29 & 40 & 71 \\
\hline Maximum & 77 & 76 & 67 & 59.91 \\
\hline Mean & 57.33 & 54.96 & 58.67 & 9.21 \\
\hline SD & 12,95 & 13.25 & 5.72 & \\
\hline
\end{tabular}

The average oflaboratory skill of X-A and X-B students were 57.33 and 54.96. While the initial laboratory skills of grade XI-A and XI-B students were 58.67 and 59.91. Generally, the average of laboratory skill of SMA X with A accreditation school was 57.72 in the medium category. The second sample was SMA with accreditation B represented by SMA Y. Descriptive analysis of laboratory skill of SMA Y with B accreditation B more in table 11. Based on descriptive analysis, the average of initial laboratory skill for grade X A and B were 60.97 and 53.75 . While for grade XI A, B and C were 64.5; 49.60 and 53.70. Generally, the average initial laboratory skills of SMA $\mathrm{Y}$ representing accreditation $\mathrm{B}$ was 56.50 in the medium category.

Table 11:-Description of initial laboratory skills SMA Y

\begin{tabular}{|l|c|c|c|c|c|}
\hline \multirow{2}{*}{ Parameter } & \multicolumn{2}{|c|}{ Grade X } & \multicolumn{3}{c|}{ Grade XI } \\
\cline { 2 - 6 } & A & B & A & B & C \\
\hline Minimum & 27 & 17 & 51 & 73 & 71 \\
\hline Maximum & 84 & 70 & 81 & 49,60 & 53.70 \\
\hline Mean & 60.97 & 53,75 & 64,5 & 13.68 & 9.93 \\
\hline SD & 13.57 & 13,09 & 6,98 & & \\
\hline
\end{tabular}

The third sample was SMA with accreditation C represented by SMA Z. The result of descriptive analysis of the initial laboratory skill in SMA Z more in table 12.

Table 12:-Descriptive initial laboratory skill of SMA Z

\begin{tabular}{|l|c|c|c|c|}
\hline \multirow{2}{*}{ Parameter } & \multicolumn{3}{|c|}{ Grade X } & \multirow{2}{*}{ Grade XI } \\
\cline { 2 - 4 } & $\mathbf{A}$ & $\mathbf{B}$ & $\mathbf{C}$ & 14 \\
\hline Minimum & 7 & 20 & 30 & 41 \\
\hline Maximum & 27 & 37 & 20.08 & 21.00 \\
\hline Mean & 17.00 & 27.50 & 4.90 & 6.24 \\
\hline SD & 5.05 & 5.30 & & \\
\hline
\end{tabular}

The result of initial laboratory skill analysis for students of grade A, B, and C was 17.00; 27.50 and 20.08. While the initial laboratory skill of the grade XI student laboratory was 21 . Generally the average initial skill of the student laboratory was 21.39 in low category.Differences of initial laboratory skills of student's high school laboratory in Ternate city can be seen in the following figure 4.

Figure 4:-Differences in initial laboratory skills of high school students in Ternate

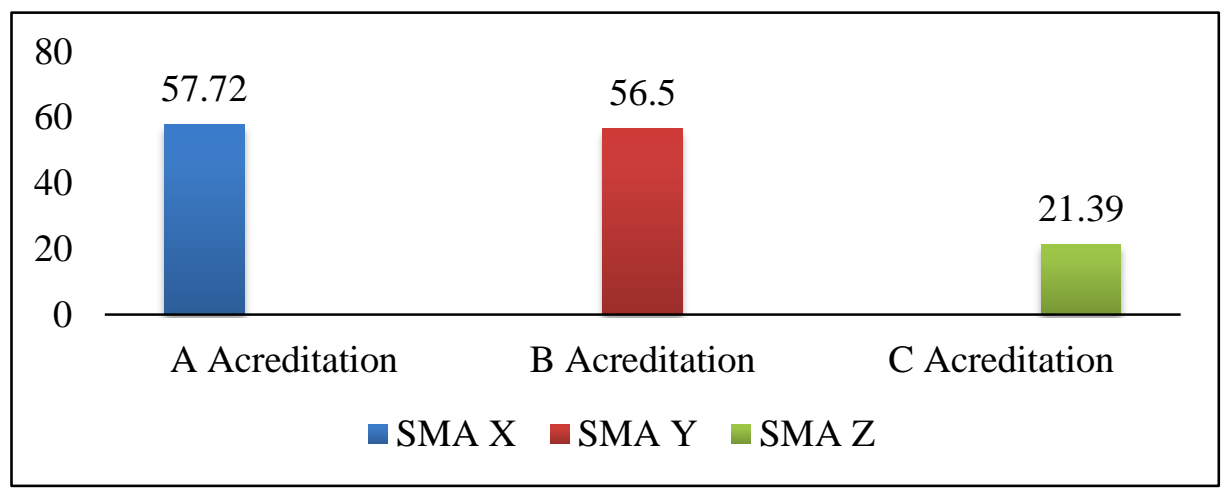


Based on the figure 4, shows that the initial ability of the laboratory of SMA Z students representing the School sample with accreditation $\mathrm{C}$ was lower than the accredited SMA X and SMA Y.

The problem of laboratory was also strengthened [8] stated that the implementation of practicum activities in the field was still gets a lot of obstacles. The problems encountered and experienced by teachers in organizing pre-work activities include lack of practicum equipment, lack of knowledge and skills of teachers in managing lab activities, practical activities or practical laboratory activities rarely implemented, practicum a lot of time and energy and teachers was also less able to plan the experiment, formulate goals, create student worksheets, manage and assess the laboratory, as well as practicum undertaken less evocative student thought processes [8].

The lack of maximum practical activities resulted in the initial laboratory skills of students in Ternate City was 45.20 in the medium category. Low laboratory skills indicator that was ability of student to use and read the measuring instrument correctly and to know the nature of a product of experiment result. Students' ability to read the right was still low when the success of a trial or experiment often depends on the ability to choose and use laboratory appropriately. While the indicators of students' ability to understand the functions, designing experiments, and doing safety practicum in case of minor accidents were in the medium category. Student laboratory skills still need to be developed. Indicators of laboratory safety or chemical safety handling also need to be developed in laboratory skills. Aspects of chemical safety and interests to be communicated to students to help avoid accidents in the laboratory. Chemical security includes: hazard identification and risk assessment, emergency response, waste management, and accident reporting and investigation. [12]. Therefore, during the learning process needs to be more laboratory skills.

Development of laboratory skills needs to be done in order to provide direct experience, first experience to the students, so as to change students' perceptions about the important things [8]. Practical work in the laboratory is very important in learning because it provides training, experience, and train students investigative skills because at the time of practicum activities involving all activities, creativity and intellectuality of students. Furthermore, The Student can more easily understand the theory if proven through the lab so that students get their learning experience [2]. Studying in the laboratory will develop students' understanding of scientific concepts, cognitive enhancement skills, and student attitudes [6]. The attitude is important to study science. Students should have a positive attitude towards the science laboratory when acquiring laboratory skills and scientific content [1].

\section{Conclusion:-}

Based on the validity value of the laboratory skill works of 3.34 in the category was very valid. The result of initial laboratory skill analysis showed that the average initial skill of student laboratory at school: (1) A accreditation was 57.72 in medium category, (2) accreditation B was 56.50 in medium category, (3) C accreditation was 21, 39 low categories. In general, the average initial laboratory skills of students in the city of Ternate was 45.20 in the medium category.

\section{Reference:-}

1. Akçayır, Murat., Akçayır,G., Pektas, H, M., Ocak,M.A. 2016. Augmented Reality In Science Laboratories: The Effects Of Augmented Reality On University Students' Laboratory Skills And Attitudes Toward Science Laboratories. Computers in Human Behavior 57 (2016) 334-342

2. Baetik, et al., 2014. Practicum Based Learning Bertisi Sert To Improve Laboratory Skills and Competition Mastery. Chemical education journal.Vol (8). Number 1)

3. Erniwati., Eso, R., \& Rahmia, S. 2014. Use of Video-Based Practical Media in Ipa-Physics Learning To Improve Student Results on Material Temperature and Its Changes. Journal of Science and Physics Education, 10 (10): Volume 10, Number 3, 269 - 273.

4. Ezeano, Alice., Ezeudu Florence. (2013). Application of Laboratory Management Skills by Chemistry Teachers in Enugu State. Journal of Education and Practice. ISSN 2222-1735 (Paper) ISSN 2222-288X (Online). Vol.4, No.18.

5. Geleta., Tolosa. (2015). How Can I Improve My Students' Ability In Doing Laboratory Practical Work On Analytical Chemistry-I? A Case on Class N23 at Kcte. Ajce, 2015, 5 (1). ISSN 2227-5835.

6. Gobaw, FG., Atagana, HI. (2016). Assessing Laboratory Skills Performance in Undergraduate Biology Students. Academic Journal of Interdisciplinary Studies MCSER Publishing, Rome-Italy. E-ISSN 2281-4612 ISSN 2281-3993. Vol 5 No. 32016. 
7. Maknun. D. (2012). Evaluation of student laboratory skills using competency-based laboratory assessment on the implementation of field experience practice (PPL). A holistic journal. Vol 13. Number 01. June 2012.

8. Maknun, D., Surtikanti., Subahar, T.S. 2012. Mapping of Essential Skills of Laboratory in Ecological Practicum Activities. JPII 1 (1) .1-7.

9. Setyaningsih. YI., Harjito. (2013). Enhancement of Laboratory skills through practical demonstrative methods on the semester credit system curriculum. Journal unnes. Chemistry education 2 (1). ISSN No.2252-6609.

10. Taglieri, C.A., Pharm. D., Crosby, S.J., Ferullo, J.W. 2014. Implementation of ACommunication Skills Laboratory. Currents in Pharmacy Teaching and Learning 6. 773-781.

11. Trianto (2010). Designing Innovative-Progressive Learning Models. Jakarta: Kencana

12. Walters, A. U.C., Lawrence, W., Jalsa, N. K.2017. Chemical Laboratory Safety Awareness, Attitudes and Practices of Tertiary Students. Safety Science 96 (2017) 161-171

13. Wiratma., Subagia. (2014) 4. Chemical laboratory management at SMA Negeri in singaraja city: (reference for development of guidance model of chemistry laboratory management based on local wisdom of Tri Sakti). Jurnal pendidikan Indonesia. Vol. 3. No 2. 